\title{
Changes in antibiotic use in a general surgery unit over a 5-year period
}

\author{
K. Ayazi, ${ }^{1}$ A. Khabaz, ${ }^{7}$ L. Ayazi, ${ }^{1,2}$ B. Ghorbani, ${ }^{3}$ M. Eslami ${ }^{7}$ and M. Ebrahimi ${ }^{7}$
}

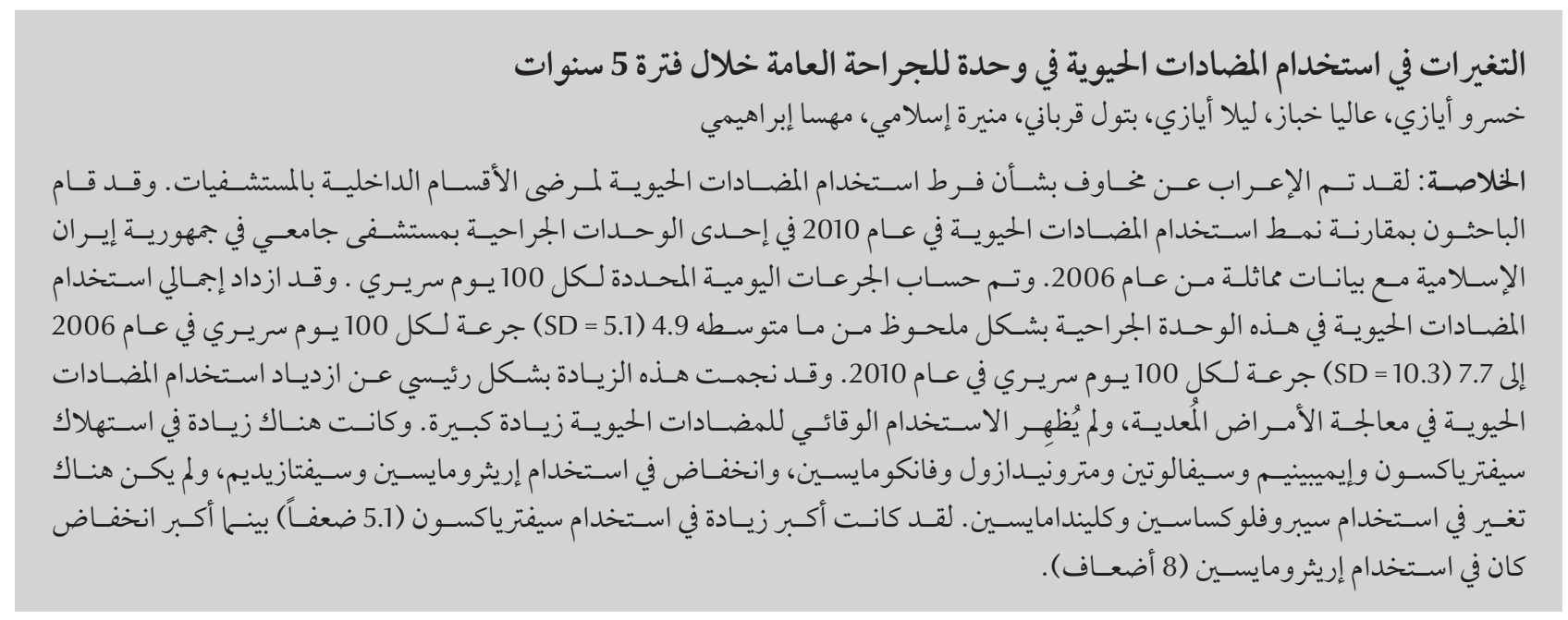

ABSTRACT Concerns have been expressed about the overuse of antibiotics in inpatient settings. We compared the pattern of antibiotic use in 2010 in a surgical unit of a university hospital in the Islamic Republic of Iran with similar data from 2006. Defined daily doses per 100 bed-days (DBD) were calculated. Overall use of antibiotics in our surgical unit increased significantly from a mean of 4.9 (SD 5.1) DBD in 2006 to 7.7 (SD 10.3) DBD in 2010. This increase was mainly due to increases in the use of antibiotics for treatment of infections; the prophylactic use of antibiotics did not show a significant increase. There was an increase in the consumption of ceftriaxone, imipenem, cefalotin, metronidazole and vancomycin, a decrease in the use of erythromycin and ceftazidime and no change in the use of ciprofloxacin and clindamycin. Ceftriaxone showed the greatest increase (5.1-fold) and erythromycin the sharpest decrease (8-fold) in use.

Modifications dans l'utilisation des antibiotiques dans un service de chirurgie générale sur une période de cinq ans

RÉSUMÉ Des préoccupations ont été formulées concernant l'utilisation excessive des antibiotiques en milieu hospitalier. Nous avons comparé le mode d'utilisation des antibiotiques en 2010 dans un service de chirurgie d'un hôpital universitaire de la République islamique d'Iran à des données similaires datant de 2006. Des doses journalières définies ont été calculées pour 100 jours-lits. L'utilisation globale des antibiotiques dans notre service de chirurgie a nettement augmenté, passant d'une moyenne de 4,9 jours-lits (E T 5,1) en 2006 à 7,7 jourslits (E T 10,3) en 2010. Cette augmentation était principalement due à l'utilisation accrue des antibiotiques pour le traitement d'infections. En revanche, l'utilisation prophylactique des antibiotiques n'a pas augmenté significativement. La consommation de ceftriaxone, d'imipénem, de céfalotine, de métronidazole et de vancomycine a augmenté, tandis que l'utilisation de l'érythromycine et de la ceftazidime a diminué et qu'aucun changement n'a été observé pour la ciprofloxacine et la clindamycine. Le recours à la ceftriaxone a connu l'augmentation la plus importante (multiplication par 5,1) tandis que la consommation d'érythromycine a connu la diminution la plus importante (division par 8).

${ }^{7}$ Department of Surgery, Imam Hossein University Hospital, Shahid Beheshti University of Medical Sciences, Tehran, Islamic Republic of Iran (Correspondence to K. Ayazi: khayazi@gmail.com).

${ }^{2}$ School of Dentistry, Shahid Beheshti University of Medical Sciences, Tehran, Islamic Republic of Iran.

${ }^{3}$ Department of Physiology, Tehran University of Medical Sciences, Tehran, Islamic Republic of Iran.

Received: 07/08/11; accepted: 21/02/12 


\section{Introduction}

Health-care-associated infections are a concern, especially in developing countries, where the rates may be higher than in industrialized countries $(1,2)$. Surgical site infections are a leading cause of health-care-associated infections and this encourages surgeons to adopt a liberal approach to prescribing antibiotics $(3-5)$. Although such as practice may seem to be beneficial in reducing infection rates in inpatient settings, it can potentially lead to emergence of resistant microorganisms and consequent increases in health-care costs. In fact the causal association between the amounts of antibiotics used and rates of resistance to antibiotics has been well established in several studies (6-9). Furthermore, antibiotics are widely used for perioperative prophylaxis in surgical units, and appropriative antibiotic prescribing for this purpose is also of great importance for monitoring quality of care, infection control and costs and to avoid the emergence of multi-resistant organisms.

There is a need for strict guidelines for antibiotic use designed for each specific geographical area to avoid overuse and misuse of antibiotics. The first step in developing such guidelines is to determine the pattern of antibiotic consumption in these countries. Previous studies in the Islamic Republic of Iran have shown a dramatic rise in antibiotic use over a 5-year period starting from $2000(3,10)$. But more recent data are not available and there are a paucity of studies that define the pattern of antibiotic use in hospitals in general and in surgical units in particular. To tackle this shortcoming we designed a study to investigate the pattern of antibiotic use in the surgical division of a university hospital in Tehran and to compare it with data obtained 5 years ago to assess if these had been a change in the trend in antibiotic use over this 5-year period. Such data will help health-care authorities to design appropriate guidelines for prescribing antibiotics in hospital settings.

\section{Methods}

\section{Study setting and sample}

This cross-sectional study was conducted in the department of surgery of Imam Hossein University Hospital. Our hospital is a tertiary referral centre for the east and south-east of Tehran and our surgical department has a dominant gastrointestinal and trauma practice. Approval for the study was obtained from the local ethics committee.

Data for the periods January 2006 to December 2006 and January 2010 to December 2010 were extracted from the charts of the patients who were admitted for general surgery in these 2 years.

\section{Data collection}

Patients' demographic and clinical data were collected. The total consumption of antibiotics for each patient in defined daily doses (DDD) was collected for all the available antibiotic substances (class J01). No medication was given to any patient without being recorded in his/her chart and all data used in this study were extracted from the patients' hospital charts. The types of surgical procedures were similar in 2006 and 2010 and there were no changes in the procedures in place within this 5-year period with regard to any recommendations for antibiotic use in our institution. The number of bed-days in the surgical unit was also recorded from each patient's chart and used for further calculations. Data from these 2 years were then compared to investigate any potential changes in antibiotic use over the 5-year period.

\section{Definitions and parameters used}

Antibiotics were defined as antibacterials for systemic use and were equivalent to group J01 of the Anatomical
Therapeutic Chemical (ATC) classification system from the World Health Organization (WHO) collaborating centre for drug statistics methodology (11). It is important to note that according to WHO the J0 1 catergory does not include antifungals, antibacterials used for treatment of tuberculosis or topical antibiotics.

Hospital bed-days measures the use of a particular hospital inpatient unit or health care institution. It can be calculated in the following way: first to determine the total inpatient days of care by adding together the daily patient census for 365 days, then to determine the total bed-days available by multiplying the total number of beds available in an inpatient unit by 365 and finally by dividing the total inpatient days of care by the total bed-days available and multiplying the result by 100 in order to express this figure as a percentage.

DDD is a WHO statistical measure of drug consumption and is used to standardize the comparative use of various drugs within drug categories or different health care environments. This parameter is used to overcome shortcomings in the use of traditional units of drug consumption and provides a fixed unit of measurement independent of price and formulation and enables the researcher to perform comparisons between population groups. This parameter is the assumed average maintenance dose per day in adults for a certain medication, when used for its main indication.

In addition to the total DDD, we also calculated defined daily doses per 100 bed-days (DBD). DBD is the number ofDDD per patient bed-days during the observation period and provides an estimate of drug consumption among hospital inpatients.

\section{Statistical analysis}

Data were entered into a Microsoft Excel database and reported as mean and standard deviation (SD), unless otherwise specified. The Student $t$-test was 
used to compare continuous variables. Differences were considered significant at $P<0.05$. Statistical analyses were performed using SPSS, version 11.5.

\section{Results}

The number of hospital bed-days in the general surgery unit of Imam Hossein University Hospital was 17800 in the year 2006 and increased to 20400 in the year 2010. The mean length of hospital stays were 4.5 (SD 2.4) and 5.1 (SD 4.9) days for the years 2006 and 2010 respectively. Appendectomy, herniorrhaphy and surgeries performed in patients with penetrating traumas were the 3 most common procedures performed in the year 2006, accounting for $40 \%$ of all operations performed in our general surgery division in this year. These operations were also the 3 most common procedures performed in the year 2010 and accounted for $43 \%$ of all surgeries performed in this year.

Injection was the most popular method of administration of the antibiotics with regard to both DDD consumption and prevalence of use. This was true for both 2006 and 2010 .

Overall use of all antibiotics in our surgical unit increased from a mean
DBD of $4.9($ SD 5.1) in 2006 to 7.7 (SD 10.3) in $2010(P=0.01)$. Use of antibiotics for prophylaxis purposes also increased from a mean DBD of 5.0 (SD 5.1) in 2006 to 6.2 (SD 7.6) in 2010 but this difference did not reach statistical significance $(P>0.05)$. When antibiotics used for prophylaxis were excluded from the analysis, the mean $\mathrm{DBD}$ were still significantly higher in 2010 compared with 2006 [6.2 (SD 7.6) versus 2.9 (SD 2.5)] (P $=0.005)$.

The comparison for overall use of antibiotics expressed as DBD for the years 2006 and 2010 are shown in Figure 1. Metronidazole, cefalotin and ceftazidime were the 3 most commonly used antibiotics in our surgical unit in 2006. This changed in 2010 and ceftriaxone, cefalotin and then metronidazole were the most prescribed antibiotics.

When the DBD data for antibiotics used for prophylaxis were analysed, metronidazole, cefalotin and ceftazidime were found to be the 3 most commonly used antibiotics in 2006, and cefalotin, ceftriaxone and metronidazole were the 3 most common in 2010. Analysis of the prevalence of antibiotic use showed that metronidazole was the most prevalent antibiotic, prescribed for $35.6 \%$ of patients in 2006. Similar analysis for 2010 showed that cefalotin was then the most prevalent antibiotic and was used for prophylaxis in $35.9 \%$ of the patients in that year (Figure 2).

Table 1 summarizes the DBD data for antibiotic use for overall and prophylaxis purposes for the years 2006 and 2010. The overall consumption of ceftriaxone, imipenem, cefalotin, metronidazole and vancomycin increased in 2010 compared with 2006. Ceftriaxone showed the highest increase in consumption, with a 5.1-fold increase in DBD (6.6 versus 34.0 ), then imipenem with a 3.2 -fold increase ( 5.5 versus 17.9) and vancomycin with a 3.1-fold increase (2.4 versus 7.7 ). In contrast, erythromycin showed an 8-fold use decrease in DBD (2.5 versus 0.3 ) and ceftazidime a 4-fold decrease (12.4 versus 3.0). Ciprofloxacin and clindamycin showed no significant change in consumption over this 5-year period.

\section{Discussion}

Antibiotics are one of the most frequently used medications among hospitalized patients in surgical units. Over recent years we have witnessed an increasing tendency for widespread and

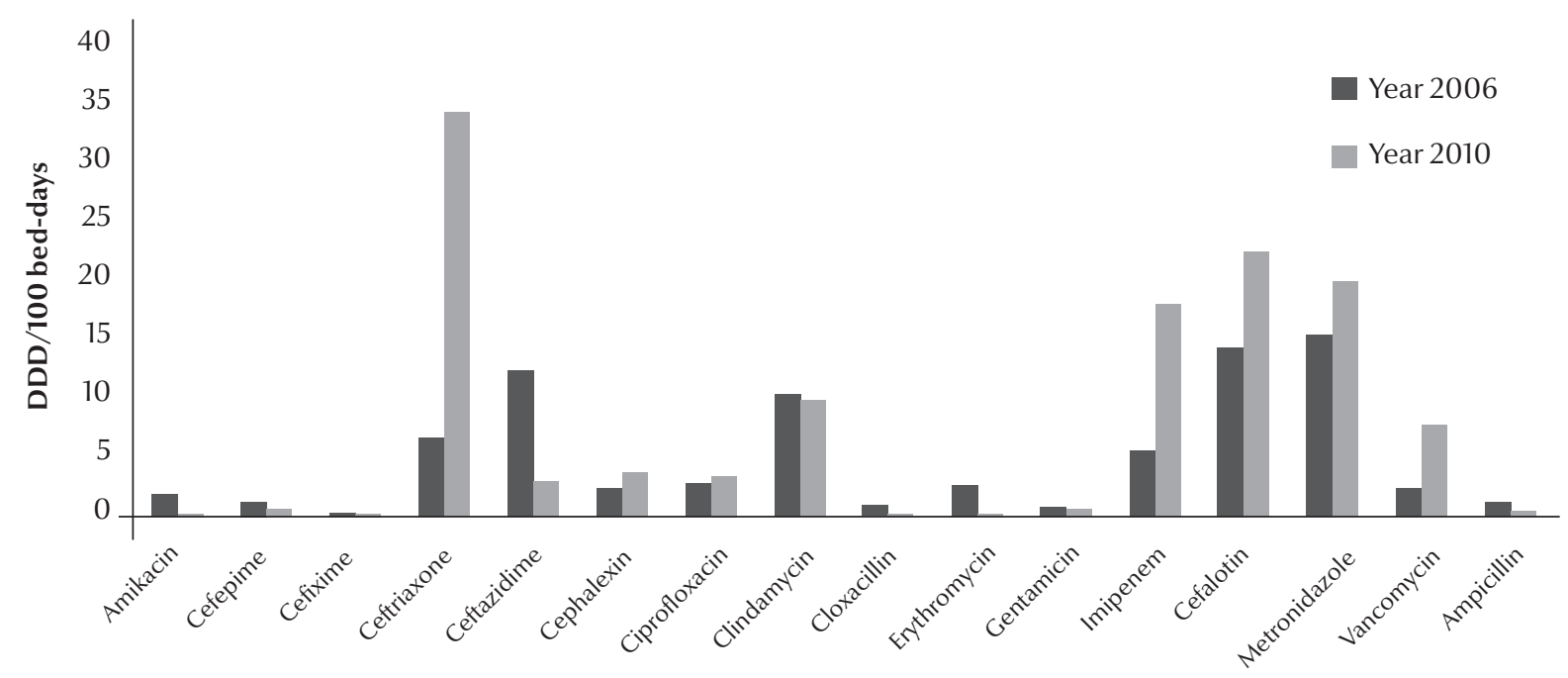

Figure 1 Overall use of antibiotic expressed as defined daily doses (DDD) per 100 bed-days in the years 2006 and 2010 


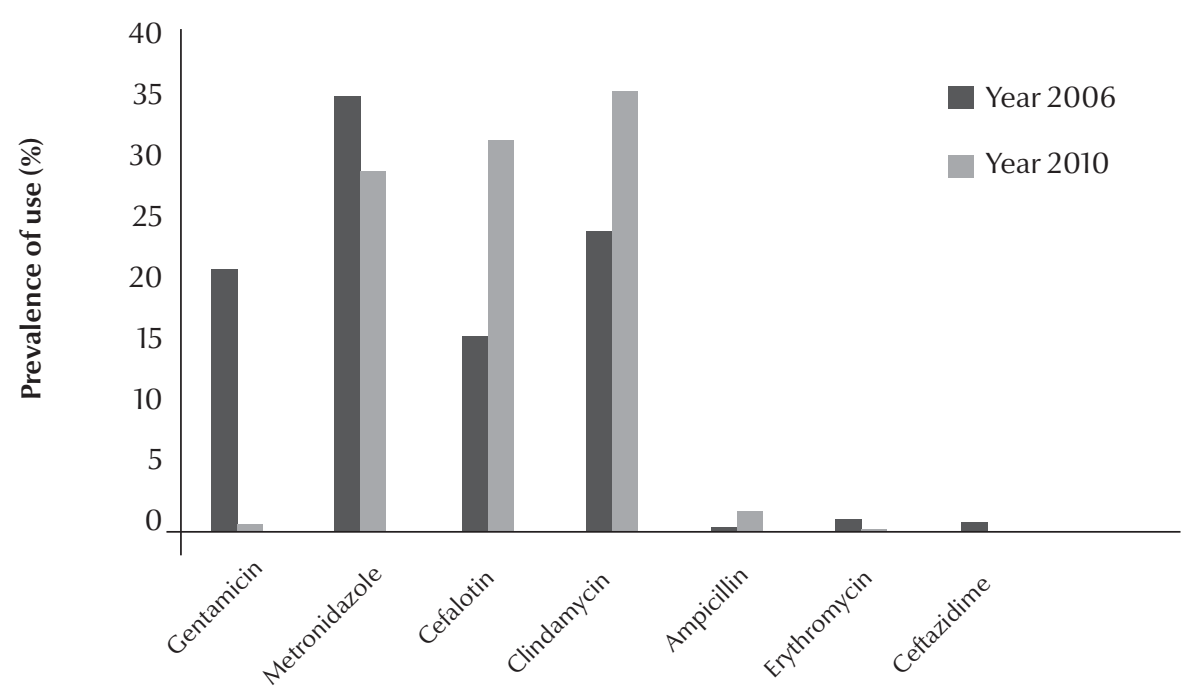

Figure 2 Prevalence of antibiotic used for prophylactic purposes in the years 2006 and 2010

indiscriminate use of newer antibiotics in surgery practice in our country. This observation is supported by data showing a dramatic raise in the use of antibiotics in the Islamic Republic of Iran and is further confirmed by our finding of a 1.6-fold increase in antibiotic use in our surgical unit over a 5-year period.

We have witnessed a decline in the numbers of new antibiotics being marketed in recent years and the medical community is struggling to preserve our current armamentarium (12). Investigators and health-care officials in the United States and Europe are working on a more uniform approach to antibiotic stewardship. The limited data available from developing countries shows that overuse and misuse of antibiotics is a very common problem in these countries. This is partially due to lack of guidelines and policies for antibiotic usage. To develop such guidelines it is necessary first to determine the pattern of antibiotic use in these counties and this was our motive for conducting the current study.

The main finding of our study was a 1.6-fold increase in antibiotic use in our surgical unit over a 5-year period ending 2010. Data on the use of antibiotics in hospital settings in the Islamic Republic of Iran are very limited and to the best of our knowledge our study was the first to assess this issue in a surgical unit in the country. Our data appear to be consistent with data published on antibiotic use trends in other countries over the same time frame. Similar increases were described in studies from Western Europe $(13,14)$ and some studies from Mediterranean and North African countries (6,7).

We also found a dramatic increase in the use of newer antibiotics in the year 2010 compared with 2006. For example, vancomycin use demonstrated a 3-fold increase in this time period in our surgical unit. This is also consistent with the findings of similar papers on this topic from other countries. A study of the use of glycopeptide antibiotics in German hospitals showed a sharp increase in consumption of these types of antibiotics over a 3-year period ending 2000 (15,16). The authors found that prophylactic and empirical indications accounted for only $50 \%$ of all prescriptions and in the remaining patients the use of this antibiotic was inappropriate and unnecessary. Over the 5-year period of our study, no change in the guidelines or recommendations was introduced in our institution and therefore market pressure may be one of the causes of this observed widespread increase in the use of new antibiotics. This is a matter of great concern as excessive use of these antibiotics increases the risk of development of resistant strains among Enterococcus spp. and Staphylococcus spp. bacteria.

We acknowledge some limitations to our study. One is the lack of microbiological information about patients' infections. This information is necessary to document whether the change in the trend of antibiotic use in our department has led to greater emergence of resistant strains. Although it may sound intuitive that a more liberal use of antibiotics is associated with development of more resistant bacteria, there is a need for future studies to correlate the data of antibiotic use to the microbiological findings to confirm this hypothesis. The second limitation of our study is that the use of DDD can potentially overestimate antibiotic use in those patients who require a higher dose. In contrast, since the DDD definition does not account for dose adaptation in children this parameter may underestimate the calculated antibiotic use in children, 


\begin{tabular}{|c|c|c|c|c|}
\hline \multirow[t]{2}{*}{ Antibiotic } & \multicolumn{2}{|c|}{$\begin{array}{l}\text { Overall use of antibiotics } \\
\text { (DBD) }\end{array}$} & \multicolumn{2}{|c|}{$\begin{array}{l}\text { Prophylactic use of antibiotics } \\
\text { (DBD) }\end{array}$} \\
\hline & Year 2006 & Year 2010 & Year 2006 & Year 2010 \\
\hline Metronidazole & 15.2 & 19.8 & 6.1 & 7.1 \\
\hline Cefalotin & 14.0 & 22.4 & 9.6 & 17.4 \\
\hline Ceftazidime & 12.4 & 3.0 & 5.6 & 0.1 \\
\hline Clindamycin & 10.3 & 9.7 & 0.7 & 0.5 \\
\hline Ceftriaxone & 6.6 & 34.0 & 0.1 & 15.7 \\
\hline Imipenem & 5.5 & 17.9 & 0.0 & 0.0 \\
\hline Ciprofloxacin & 2.8 & 3.4 & 0.0 & 0.0 \\
\hline Erythromycin & 2.5 & 0.3 & 0.0 & 0.0 \\
\hline Vancomycin & 2.4 & 7.7 & 0.0 & 0.0 \\
\hline Cephalexin & 2.3 & 3.7 & 0.0 & 0.0 \\
\hline Amikacin & 1.7 & 0.2 & 0.0 & 0.0 \\
\hline Cefepime & 1.2 & 0.6 & 0.0 & 0.0 \\
\hline Ampicillin & 1.1 & 0.4 & 0.5 & 0.5 \\
\hline Cloxacillin & 1.0 & 0.2 & 0.0 & 0.0 \\
\hline Gentamicin & 0.7 & 0.6 & 0.5 & $<0.1$ \\
\hline Cefixime & $<0.1$ & 0.0 & 0.0 & 0.0 \\
\hline
\end{tabular}

who usually take antibiotics in dosages lower than adults. However, the majority of patients admitted to our surgical unit were adults and this limitation is unlikely to have affected our results.

In conclusion, a logical approach to managing infected patients and to the use of preoperative prophylactic antibiotics in surgical units is necessary. Such an approach requires strict guidelines that allow appropriate selection of antibiotics and limits overuse and misuse of antimicrobial agents. In the absence of such guidelines, there is a risk that other influences will shape the pattern of antibiotic use and will lead to an increase in the overall consumption of antibiotics and in particular the new broad-spectrum ones.

Competing interests: None declared..

\section{References}

1. Wenzel RP, Edmond MB. The impact of hospital-acquired bloodstream infections. Emerg Infect Dis. 2001 MarApr;7(2):174-7. PMID:11294700

2. Eriksen HM, Iversen BG, Aavitsland P. Prevalence of nosocomial infections in hospitals in Norway, 2002 and 2003. J Hosp Infect. 2005 May;60(1):40-5. PMID:15823655

3. Yousefi Z, Zazouli MA. Misuse of antibiotics in a hospital, an environmental health problem. World Applied Sciences Journal. 2008;3:555-8

4. van Kasteren ME, Mannien J, Kullberg BJ, de Boer AS, Nagelkerke NJ, Ridderhof M, et al. Quality improvement of surgical prophylaxis in Dutch hospitals: evaluation of a multi-site intervention by time series analysis. J Antimicrob Chemother. 2005 Dec;56(6):1094-102. PMID:16234334

5. Nyamogoba $\mathrm{H}$, Obala AA. Nosocomial infections in developing countries: cost effective control and prevention. East Afr Med J. 2002 Aug;79(8):435-41. PMID:12638846

6. Vaccheri A, Silvani MC, Bersaglia L, Motola D, Strahinja P, Vargiu A, et al. A 3 year survey on the use of antibacterial agents in five Italian hospitals. J Antimicrob Chemother. 2008 Apr;61(4):953-8. PMID:18218639
7. Borg MA, Zarb P, Ferech M, Goossens H; ARMed Project Group. Antibiotic consumption in southern and eastern Mediterranean hospitals: results from the ARMed project. J Antimicrob Chemother. 2008 Oct;62(4):830-6. PMID:18593724

8. Kuster SP, Ruef C, Bollinger AK, Ledergerber B, Hintermann A, Deplazes C, et al. Correlation between case mix index and antibiotic use in hospitals. J Antimicrob Chemother. 2008 Oct;62(4):837-42. PMID:18617509

9. Vander Stichele RH, Elseviers MM, Ferech M, Blot S, Goossens $\mathrm{H}$; European Survaillance of Antibiotic Comsuption (ESAC) Project Group. Hospital consumption of antibiotics in 15 European countries: results of the ESAC Retrospective Data Collection (1997-2002). J Antimicrob Chemother. 2006 Jul;58(1):159-67. PMID:16698845

10. Ebrahimzadeh MA, Shokrzadeh M, Ramezani A. Utilization pattern of antibiotics in different wards of specialized Sari Emam University Hospital in Iran. Pak J Biol Sci. 2008 Jan 15;11(2):275-9. PMID:18817203

11. ATC/DDD index 2012. WHO Collaborating Centre for Drug Statistics Methodology [Internet] (http://www.whocc.no/ atcddd/, accessed 27 November 2012). 
12. Mainous AG 3rd, Diaz VA, Matheson EM, Gregorie SH, Hueston WJ. Trends in hospitalizations with antibiotic-resistant infections: U.S., 1997-2006. Public Health Rep. 2011 MayJun;126(3):354-60. PMID:21553664

13. Müller-Pebody B, Muscat M, Pelle B, Klein BM, Brandt CT, Monnet DL. Increase and change in pattern of hospital antimicrobial use, Denmark, 1997-2001. J Antimicrob Chemother. 2004 Dec;54(6):1122-6. PMID:15537692

14. Janknegt R, Oude Lashof A, Gould IM, van der Meer JW. Antibiotic use in Dutch hospitals 1991-1996. J Antimicrob Chemother. 2000 Feb;45(2):251-6. PMID:10660512
15. Kern WV, De With K, Gonnermann C, Strehl E, Bergner J, Höffken G, et al.; Medical Antibiotic Use Surveillance and Evaluation. Update on glycopeptide use in German university hospitals. Infection. 2004 Jun;32(3):157-62. PMID:15188076

16. Kern WV, de With K, Trautmann M, Kern P, Gonnermann C. Glycopeptide use at four university hospitals in southern Germany. Infection. 2002 Oct;30(5):262-6. PMID:12382083 